\title{
UMA APRECIAÇÃO À EDUCAÇÃO INCLUSIVA NOS CURSOS DE LICENCIATURA DE MATEMÁTICA DO ESTADO DO ACRE
}

\author{
Cristhiane de Souza Ferreira ${ }^{1}$ \\ Maria Aparecida Santos e Campos²
}

RESUMO: As instituições que formam professores vêm sendo estimuladas pelas legislações a repensarem suas estratégias didáticas para receber e formar os futuros professores para uma sociedade mais inclusiva. A Resolução CNE/CP № I/2002 designa diretrizes para a formação de professores em busca de respaldar uma perspectiva inclusiva e determina que as instituições de ensino superior prevejam, em sua organização curricular, formação docente continuada de forma a atender a diversidade e analisem as informações sobre as especificidades de cada aluno. Apesar das leis destinadas à normatizar o processo de inclusão de todos os alunos, muitos professores não possuem uma formação adequada para incluir alunos com necessidades específicas e, assim não se sentem preparados para enfrentar tal desafio. O objetivo deste estudo é analisar como os cursos de Licenciatura em Matemática do Estado do Acre tratam as questões da educação inclusiva em seus PPCS. Como método foi utilizado a pesquisa quali-quantitativa por possuir características complementares e favorecer a interpretação de um mesmo fenômeno estudado utilizando a abordagem de diferentes técnicas simultaneamente. Para a técnica de coleta de dados foi utilizada a análise documental, uma vez que, buscou-se extrair dos Projetos Pedagógicos dos Cursos Superior (PPCS) de Matemática, um reflexo das informações nele contidas. Os resultados revelam que apesar de pareceres e resoluções respaldarem uma perspectiva inclusiva, a temática ainda é tratada com apoio a alunos com deficiência, transtornos globais de desenvolvimento e altas habilidades/superdotação. Conclui-se

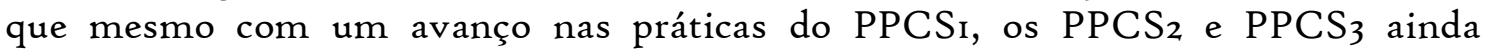
necessitam melhorar em relação a Prática de Ensino e, principalmente nas práticas de Estágio Supervisionado para cumprir as novas diretrizes de Educação Inclusiva.

Palavras-chave: Educação matemática. Formação inicial. Projeto pedagógico do curso.

\footnotetext{
I Doutoranda em Educação pela Universidad Internacional Iberoamericana (UNINI- MX). Mestra Profissional em Ensino de Ciências e Matemática pela Universidade Federal do Acre (2017). Especialista em Educação Inclusiva pela Faculdade de Educação Acriana Euclides da Cunha (2016). Licenciada em Matemática pela Universidade Federal do Acre (2008). Professora do Instituto Federal do Acre, campus Rio Branco. Orcid oooo-ooo2-1738-87. E-mail: cristhiane.ferreira@ifac.edu.br.

${ }^{2}$ Doctor en Actividad Física y Salud por la Universidad de Jaén (2013), Máster en Estudios Avanzados - DEA por la Universidad de Jaén (2009), Graduado en Licenciatura en Educación Física por el Instituto Católico de Minas Gerais (1992). Catedrático de Actividades Terapéuticas de la Asociación Jienense de Fibromialgia e Investigador Colaborador de la Universidad de Jaén. Orcid oooo-ooor-7190-5438. Correo electrónico: maria.santos@unini.edu.mx.
} 


\section{INTRODUÇÃO}

A formação inicial de professores é a base que proporciona a construção do conhecimento pedagógico e, para compor uma formação sólida, as instituições educacionais de ensino superior devem subjugar a compreensão de que a educação escolar é um conjunto de saberes prodigiosos. Esta pesquisa abrange a formação inicial de professores de Matemática, em particular no que se refere a educação inclusiva, que para Canassa e Borges (2020, p.8) "vem se constituindo como um aspecto de destaque dentro das políticas públicas que têm orientado a ação docente em matemática em sala de aula".

A importância em compreender o perfil do professor que ensina Matemática em um contexto inclusivo torna-se um processo complexo, relevante e indispensável. De um lado, tem-se os documentos que procuram orientar e organizar as escolas; por outro, as distintas realidades socioeconômicas oriundas de aspectos culturais e do abismo social. Deve-se considerar que o currículo analisado foi determinado e organizado previamente à sua implementação com a conjectura de orientar a proposta em ação, que versa sobre a forma de adaptação/flexibilização ao aluno, em sala de aula, segundo Sacritán (2013), já em situação de ensino.

Logo, para compreender como vem acontecendo essa formação, toma-se como objeto principal os Projetos Pedagógicos dos Cursos Superior (PPCS) de Matemática, em razão de que esses são os documentos oficiais que relatam a proposta de formação docente nas Instituições de Ensino Superior públicas do Estado do Acre. As instituições formadoras, Universidade Federal do Acre (UFAC) e Instituto Federal do Acre (IFAC) vem sendo estimuladas a repensarem suas estratégias didáticas para receber e formar os futuros professores para uma sociedade mais inclusiva.

Os cursos de Licenciatura em Matemática, segundo Paula, Guimarães e Silva (2018) devem atender as demandas da educação atual para que os docentes possam oportunizar aos licenciandos, "as condições necessárias para sua formação intelectual, social e moral” (p.4). Esses cursos possuem um papel indispensável na formação do futuro professor já que lhe cabe proporcionar além do conhecimento profissional, os saberes que compreendem os aspectos da profissão docente. 
O futuro docente, além de desenvolver os saberes teórico-científicos, pode aprender a lidar com as mudanças sociais ao conviver com as dificuldades e limitações intrínsecas a esse ambiente. Nesse aspecto, é apontado por Pimentel (2012) que "a inclusão educacional requer professores preparados para atuar na diversidade, compreendendo as diferenças e valorizando as potencialidades de cada estudante de modo que o ensino favoreça a aprendizagem de todos" (p.I40).

Contudo, apesar da leis destinadas a normatizar o processo de inclusão de todos os alunos, existe uma necessidade a ser suprida nos curso de Licenciatura em Matemática. Muitos professores não possuem uma formação adequada para incluir alunos com necessidades específicas e, assim não se sentem preparados para enfrentar tal desafio. A ausência desta formação, ibidem Pimentel (2012) produz o fenômeno da pseudoinclusão que configura a presença física do aluno em sala de aula, mas o mesmo não participa de forma ativa do processo de aprender.

À luz do exposto, o objetivo é analisar como os cursos de Licenciatura em Matemática tratam as questões da Educação Inclusiva em seus PPCS.

\section{REFERENCIAL TEÓRICO}

A contemporaneidade traz consigo uma afluência de amplitude mundial em defesa do direito à educação de todos, passando por várias etapas no contexto societário, desde a inclusão social, em que a sociedade é marcada por segregação, exclusão e marginalização até a inclusão escolar, possibilitando inserir aqueles que são caracterizados como diferentes por não se comunicarem ou interagirem com o mundo do mesmo modo que a maioria.

A Constituição da República Federativa do Brasil (1988) assegura o direito de todos a inclusão escolar, fazendo emergir movimentos que fizessem valer essa declaração. Já a Declaração de Salamanca (1994) foi construída em um encontro internacional em que foram elaboradas reformulações nas políticas públicas e nos sistemas educacionais no que concerne à inclusão. Seu escopo é fornecer educação de qualidade a todos considerando as características e interesses individuais de cada aluno para evitar a discriminação e a exclusão escolar. 
Nesse aspecto, sugeriu-se que as instituições educacionais se organizem e se capacitem para atender a todos, tendo em vista que não basta a afirmativa legal de oferecer condições de acesso e permanência do alunado no ambiente educacional. $O$ que se percebe é a ausência de tal preparação e o desafio de minimizar as dificuldades para desenvolver um trabalho que permeie contribuir com o processo de inclusão, de modo mais específico à docência em Matemática.

A Lei de Diretrizes e Bases da Educação Nacional no 9.394/1996 garantiu o direito de todos à educação e evidenciou a função docente ao instituir os programas de formação continuada para os profissionais de educação dos diversos níveis para que o professor potencialize a convivência social, cultural, colaborativa e democrática em qualquer nível que exercer sua profissão.

O Plano Nacional de Educação sob a Lei no $10.172 / 2001$ determina objetivos e metas para que as instituições de educação propiciem atendimento às necessidades educacionais especiais dos alunos e salienta, dentre outros, uma deficiência pertinente à formação docente. A Resolução CNE/CP № I/2002 designa as Diretrizes Curriculares Nacionais para a Formação de Professores da Educação Básica em busca de respaldar uma perspectiva de Educação Inclusiva e designa que as instituições de Ensino Superior prevejam, em sua organização curricular, formação docente continuada de forma a atender a diversidade e analisem as informações sobre as especificidades de cada aluno.

O Programa de Educação Inclusiva: direito à diversidade fornecido pelo Ministério da Educação e Cultura entre 2003 e 2007 promoveu a formação de gestores e professores das escolas estaduais e municipais de ensino para serem multiplicadores da educação especial na perspectiva da educação inclusiva aptos a formar outros gestores e educadores. Seu objetivo foi proporcionar as redes atenderem com qualidade e incluírem nas classes comuns de ensino regular alunos com deficiência, transtornos globais do desenvolvimento e altas habilidades ou superdotação.

Por fim, o movimento nacional pela Educação Inclusiva foi consolidado com a Política Nacional de Educação Especial na Perspectiva da Educação Inclusiva (2008), prevendo na educação superior, ações culturais, políticas, pedagógicas e sociais que 
promovessem o acesso, a permanência e a participação de todos os alunos. Com a nova proposta de Educação Inclusiva surge um novo paradigma educacional respaldado, ibidem (2008, s/p) "na concepção de direitos humanos, que conjuga igualdade e diferença como valores indissociáveis, e que avança em relação à idéia de equidade formal ao contextualizar as circunstâncias históricas da produção de exclusão de dentro pra fora da escola”.

A Educação Inclusiva é um novo paradigma educacional que pode ser entendida "como um processo de transformação de valores e ações, resultando em práticas e serviços educacionais em sistemas e estruturas que incorporam tais valores" (Unesco, 2009, p.2I). Esse processo contínuo objetiva oferecer educação de qualidade a todos, respeitando a diversidade, as diferentes necessidades, as habilidades, as características e as expectativas de aprendizagem de cada aluno, mas segundo Ainscow (2009, p.2I) “a inclusão só poderá ser totalmente compreendida quando seus valores fundamentais forem exaustivamente clarificados em contextos particulares”.

A Educação Matemática é uma área de pesquisa que interessa-se pelo significado que a Matemática reconhece no ato de aprender e ensinar ao mesmo tempo que a formação de professores. Para Krans (2011), dentro dessa área de pesquisa existem pesquisadores preocupados com "a inclusão de todos os alunos no processo de construção do conhecimento matemático na escola, permeado e permeando o contexto sócio-histórico do sujeito" (p.I).

Nota-se que a Matemática Inclusiva é um tópico novo para a Educação Matemática, e pequena é a quantidade de pesquisas sobre o tema. Para Rodrigues (2015, p.85) “existem vários pesquisadores que acreditam na proposta de uma Educação Inclusiva e estão empenhados em propor sugestões para o trabalho com as diferenças em salas de aula regulares inerentes as práticas do professor de Matemática”.

A Educação Matemática Inclusiva almejada por pesquisadores como (D’Ambrósio, 2013; Ramos, 2015; Barros, 2017; Canassa e Borges, 2020; Araújo e Bazante, 2020; Costa, Silva e Noronha, 2021) refere-se à aprendizagem de todos os alunos em um mesmo ambiente educacional caracterizado pelas diferenças favorecendo a interação, a linguagem, a consciência e as ações. A missão do professor, 
em particular do professor de Matemática, é "usar sua disciplina como instrumento para atingir os objetivos maiores da Educação" (D’Ambrósio, 2013, p. 2).

Este campo de pesquisa, vem sendo evidenciado por surgirem múltiplos desafios para uma prática docente em Matemática. Para tanto, deve-se subordinar o currículo ao compromisso de construir culturas educacionais para que cada aluno seja reconhecido e respeitado em sua individualidade. Os desafios que emergem na inserção de uma diversidade de alunos, em sala de aula regular, são apresentados por Pimentel (2015, p.12) "como alguma dificuldade de aprendizagem, e outros por possuírem alguma disfunção cerebral, podendo ser verificada como um transtorno de aprendizagem e que nem sempre é possível ser detectado pelo professor”.

As leis determinam alterações, cobradas por documentos internacionais que contam com a adesão de nosso país. Esses documentos contém, segundo Rodrigues (2015, p.85) "uma série de mudanças necessárias para a inclusão que abrange espaço físico, práticas pedagógicas e materiais para uso em sala de aula, além de formação inicial e continuada para os educadores".

Para que os gestores obedeçam as normas legais, orientadas por pareceres e resoluções como a CNE/CES no 3/2003 que estabelece as Diretrizes Curriculares para os cursos de Matemática tem-se os PPCS, considerados por Marcatto (2012) como documento de orientação acadêmica que deve contemplar "o perfil dos alunos; as competências e habilidades de caráter geral e específico; os conteúdos curriculares de formação geral e específica; a estrutura do curso; o formato dos estágios; as atividades complementares e as formas de avaliação" (p.42).

Os PPCS a partir do Decreto no 5.626/2005 começou a inserir a disciplina de Libras, de forma obrigatória nos cursos de Licenciaturas. A Resolução no or/2010 adequa o Núcleo Docente Estruturante (NDE) e dá outras deliberações a Comissão Nacional de Avaliação da Educação Superior (CONAES) sob o Parecer CONAES no 4/2010. A Resolução no I/2010, ainda determina que o NDE "de um curso de licenciatura constitui-se de um grupo de docentes, com atribuições acadêmicas de acompanhamento, atuante no processo de concepção, consolidação e contínua atualização do projeto pedagógico do curso” (p.I). 
Esses documentos são apontados pelo Sistema Nacional de Avaliação da Educação Superior (SINAES), criado em 2004, como dispositivos de regulamentação dos cursos de licenciatura no Brasil durante os processos avaliativos de autorização, reconhecimento e renovação.

Para Borges, Cyrino e Nogueira (2020) os cursos de FPM são continuamente impelidos a "por um lado, prezar as características locais do contexto de onde e para onde são pensados, e, por outro, garantir o respeito a outros direcionamentos externos, como os propostos pelas políticas públicas de formação de professores” (p.135). O parecer CNE/CES 1.302/2001 sobre as Diretrizes Curriculares Nacionais para os cursos de Bacharelado e Licenciatura em Matemática apresenta indicativos de assuntos a serem observadas pelos cursos, mas com flexibilidade para se refletir a formação almejada. Nota-se que o parecer considera parcialmente, a autonomia dos cursos na idealização do currículo orientador do futuro professor de Matemática para atender a diversidade cultural brasileira.

Dessa forma, houve um avanço das políticas públicas para estabelecer uma educação de qualidade a todos. No entanto, o que se pode observar na prática é que a legislação não garante que a inclusão aconteça em sala de aula, posto que promover acesso estrutural, atitudinal, metodológico e arquitetônico aos alunos têm se manifestado um desafio às instituições educacionais.

\section{PROCEDIMENTO METODOLÓGICO}

Com a intenção investigar como vem sendo abordado o tema da Educação Inclusiva nos cursos de Licenciatura em Matemática foi realizada uma análise nos Projetos Pedagógicos do Curso Superior (PPCS) de Matemática no Estado do Acre. As instituições responsáveis pela formação de professores de Matemática no estado são a Universidade Federal do Acre (UFAC) que possui cinco cursos funcionando de maneira independente em cada campi, de acordo com a realidade local; e o Instituto Federal do Acre (IFAC), que possui dois cursos, em campi diferentes. Como procedimento metodológico, optou-se pela pesquisa quali-quantitativa do tipo documental. 
A pesquisa quali-quantitativa possui características complementares e favorece a interpretação de um mesmo fenômeno estudado utilizando a abordagem de diferentes técnicas simultaneamente. Para Knetchel (2014), além da complementaridade das abordagens, a pesquisa quali-quanti proporciona a explicação da "informações quantitativas por meio de símbolos numéricos e dados qualitativos mediante a observação, a interação participativa e a interpretação” (p.ro6) que o pesquisador pode realizar do fenômeno estudado.

Para Gil (2017), a pesquisa documental, como relatórios e documentos oficiais, é uma abundante fonte de informações que ainda não recebeu tratamento analítico, ou que ainda pode ser reformulado de acordo com a situação social, econômica e cultural de um ambiente em determinado momento da pesquisa. O objetivo da pesquisa documental é identificar os dados fornecidos pelos PPCS para que se obtenha uma estrutura consistente que oriente responder o questionamento desta pesquisa.

Nesse aspecto, Gil (2017) e Bardin (2016) estabelecem a necessidade de três etapas para a técnica de coleta de dados e análise documental: identificar e localizar as fontes; organizar o material; e analisar os dados coletados. Dessa forma, os documentos foram identificados, as suas informações foram coletadas, organizadas, descritas, quantificadas, contextualizadas e analisadas. Salienta-se que buscou-se extrair dos documentos um reflexo das informações nele contidas.

$\mathrm{Na}$ etapa de identificar as fontes, foram considerados os PPCS de Matemática da UFAC, atualizados entre 2015 e 2018; e do IFAC, atualizados entre 2017 e 2018 obedecendo a Resolução no 2/2015 que define as Diretrizes Curriculares Nacionais para a Formação Inicial em Nível Superior referente aos cursos de Licenciatura. Dessa forma, tem-se como fontes sete PPCS, a saber 5 da UFAC e 2 do IFAC.

Para localizar as fontes e obter os documentos foi realizada uma busca nos sites institucionais para obter os PPCS vigentes, mas nem todos encontravam-se disponíveis. Também foi enviada uma solicitação via e-mail as coordenações dos cursos, porém nem todos responderam com prontidão para que fosse verificada a veracidade e análise da última versão aprovada. Destaca-se que o propósito era ter todos os PPCS em mãos para análise, mas não foi possível pela ausência de retorno. 
Por fim, foram obtidos 3 PPCS e 2 Matrizes Curriculares (MC), na modalidade presencial e, pretende-se analisar se as instituições estão organizando e desenvolvendo a prática da Educação Inclusiva.

Após a obtenção de parte dos documentos solicitados, iniciou-se a segunda etapa de organização do material que envolve a leitura dos PPCS. Em seguida foi organizado um fichamento com observação aos termos que surgem com certa frequência, as formas que foram inseridas nas matrizes curriculares e as nas respectivas ementas. Para viabilizar o delineamento do documento objetiva-se responder: como os cursos de Licenciatura em Matemática tratam as questões da Educação Inclusiva em seus PPCS e como estes abordam o tema em meio a um ambiente historicamente excludente?

Este questionamento possui a intenção de verificar se as instituições formadoras consideram preparar o futuro professor de Matemática para os desafios da Educação Básica no que se refere a Educação Inclusiva, tendo em vista que Leis, Pareceres e Resoluções estão sendo implementados para atender a todos os alunos com ensino de qualidade. Com a intenção de garantir o anonimato dos cursos, a identificação não foi mencionada durante a descrição e análise dos dados, sendo eles apresentados como PPCS I, PPCS 2 e PPCS 3 , conforme identificado na tabela I.

Tabela I: Percentual de disciplinas que abrangem a Educação Inclusiva na matriz curricular do curso.

\begin{tabular}{|c|c|c|c|}
\hline & $\begin{array}{c}\text { Total de } \\
\text { disciplinas } \\
\text { obrigatórias }\end{array}$ & $\begin{array}{c}\text { Disciplinas obrigatórias voltadas para a } \\
\text { Educação Inclusiva }\end{array}$ & $\begin{array}{c}\% \\
\text { Aproximado }\end{array}$ \\
\hline PPCS $_{1}$ & 52 & IO & $19,3 \%$ \\
\hline PPCS $_{2}$ & 58 & 3 & $5,2 \%$ \\
\hline PPCS $_{3}$ & 52 & 3 & $5,7 \%$ \\
\hline
\end{tabular}

Nota: Elaboração da autora.

Esse foi o primeiro momento de aproximação com os dados descritivos e oportunidade para observar plenamente a estrutura da pesquisa. Para responder o questionamento notou-se que os PPCS contemplam pelo menos três disciplinas obrigatórias voltadas para a Educação Inclusiva. Foi possível observar, ainda, aspectos 
da fundamentação legal como meio de realizar o tratamento das informações contidas nos referidos documentos.

A Resolução $\mathrm{CNE} / \mathrm{CP} \mathrm{N}^{\circ} \mathrm{I} /$ 2002, já mencionada anteriormente, cria diretrizes para a formação de professores e sobre Educação Inclusiva orienta que a formação deve preparar o docente para acolher e se comunicar com a diversidade. Já a Resolução $\mathrm{CNE} / \mathrm{CES} \mathrm{N}{ }^{\circ} 3 / 2003$, expressa previamente, estabelece orientações para que os cursos de Matemática formulem os PPCS quanto aos componentes curriculares do referido curso. Tais resoluções não foram identificadas na fundamentação legal dos PPCS.

O Decreto № 5.626/2005 regulamenta a Lei № $10.436 / 2002$ e determina que a Língua Brasileira de Sinais (LIBRAS) deve ser inserida como disciplina obrigatória nos cursos de formação de professores. Por outro lado, o Ministério da Educação por meio da Secretaria de Educação Especial propõe a Política Nacional da Educação Especial na Perspectiva da Educação Inclusiva (2008), mas a temática ainda é tratada com apoio a alunos com deficiência, transtornos globais de desenvolvimento e altas habilidades/superdotação, o que leva a concluir que não atende a todos os alunos como é a proposta da Educação Inclusiva. Apesar do Decreto e da Política Nacional não serem identificadas na fundamentação legal dos PPCS, estes já estão sendo obedecidos.

A Resolução № 2/2015, já referida anteriormente, define diretrizes para adequar, em seus PPCS, as novas diretrizes de Educação Inclusiva. Tópicos como carga horária mínima, atividade teórico-prática, prática de componente curricular, estágio supervisionado e atividade complementar estão sendo obedecidas conforme o projeto do curso de cada instituição. Entretanto, a fundamentação teórica e o regulamento de estágio ainda precisam de uma atenção mais específica. Ver tabela 2.

Tabela 2: Orientações da Resolução no 2/2015 em cada PPCS analisado

\begin{tabular}{|l|c|c|c|}
\hline \multicolumn{1}{|c|}{ RESOLUÇÃO № 2/2015 (horas) } & PPCSI (h) & PPCS2 $_{2}(\mathrm{~h})$ & $\mathrm{PPCS}_{3}(\mathrm{~h})$ \\
\hline Carga horária mínima - 3.200 h & 3.595 & 3.330 & 3.210 \\
\hline Atividade teórico-prática - 2.200 h & 2.895 & 2.209 & 2.210 \\
\hline $\begin{array}{l}\text { Prática de componente curricular - } \\
\text { 400 h }\end{array}$ & 405 & 521 & 400 \\
\hline Estágio supervisionado - 400 h & 405 & 400 & 400 \\
\hline Atividade complementar - 200 h & 200 & 200 & 200 \\
\hline
\end{tabular}

Nota: Elaboração da autora. 
Questões como prática de ensino, estágio supervisionado, ciência da educação e componentes voltados para a Educação Inclusiva foram anotados por possibilitarem uma discussão sobre o tema, conforme mostra tabela 3.

Tabela 3: PPCS com carga horária voltada para a Educação Inclusiva em Prática de Ensino, Estágio Supervisionado e Ciência da Educação conforme orientação da Resolução no 2/2015.

\begin{tabular}{|c|c|c|c|}
\hline \multicolumn{4}{|c|}{ PRÁTICA DE ENSINO } \\
\hline & $\begin{array}{l}\text { Carga } \\
\text { horária }\end{array}$ & $\begin{array}{c}\text { Carga horária voltada para a Educação } \\
\text { Inclusiva }\end{array}$ & Percentual (\%) \\
\hline PPCSI & 405 & 105 & 30 \\
\hline $\mathrm{PPCS}_{2}$ & 400 & 120 & 30 \\
\hline $\mathrm{PPCS}_{3}$ & 521 & 60 & II, 5 \\
\hline \multicolumn{4}{|c|}{ ESTÁGIO SUPERVISIONADO } \\
\hline & $\begin{array}{l}\text { Carga } \\
\text { horária }\end{array}$ & $\begin{array}{c}\text { Carga horária voltada para a Educação } \\
\text { Inclusiva }\end{array}$ & Percentual (\%) \\
\hline PPCSI & 405 & 135 & 33,3 \\
\hline $\mathrm{PPCS}_{2}$ & 400 & o & - \\
\hline $\mathrm{PPCS}_{3}$ & 400 & o & - \\
\hline \multicolumn{4}{|c|}{ CIÊNCIA DA EDUCAÇÃO } \\
\hline & $\begin{array}{l}\text { Carga } \\
\text { horária }\end{array}$ & $\begin{array}{c}\text { Carga horária voltada para a Educação } \\
\text { Inclusiva }\end{array}$ & Percentual (\%) \\
\hline PPCSI & 705 & 435 & $6 \mathrm{I}, 7$ \\
\hline $\mathrm{PPCS}_{2}$ & 545 & 240 & 44 \\
\hline $\mathrm{PPCS}_{3}$ & 525 & 180 & 34,3 \\
\hline
\end{tabular}

Nota: Elaboração da autora.

As ementas também trazem informações relevantes sobre o tema e ao associálas a matriz currículos dos PPCS pode-se compreender melhor a distribuição das disciplinas voltadas a Educação Inclusiva com suas respectivas cargas horárias. Para manter o anonimato dos documentos serão utilizados códigos para representá-los, de acordo com a tabela 4 . 
Tabela 4: Disciplinas obrigatórias com suas respectivas cargas horárias sobre Educação Inclusiva apresentadas por semestre.

\begin{tabular}{|c|c|c|c|c|c|c|c|c|}
\hline \multicolumn{9}{|c|}{$\begin{array}{l}\text { DISCIPLINAS OBRIGATÓRIA VOLTADAS PARA EDUCAÇÃO } \\
\text { INCLUSIVA }\end{array}$} \\
\hline \multicolumn{3}{|c|}{ PPCSI $_{\mathbf{I}}$} & \multicolumn{3}{|c|}{$\mathrm{PPCS}_{2}$} & \multicolumn{3}{|c|}{$\mathrm{PPCS}_{3}$} \\
\hline Sem. & Código & Horas & Sem. & Código & Horas & Sem & Código & Horas \\
\hline $\mathbf{I} \mathbf{o}$ & - & - & I음 & - & - & Io & - & - \\
\hline 20 & $\begin{array}{l}\text { CELAI7 } \\
8\end{array}$ & 60 & 2 은 & - & - & 2 은 & - & - \\
\hline $3^{\circ}$ & $\begin{array}{l}\text { CELA97 } \\
3\end{array}$ & $6 o$ & $3^{\circ}$ & 20 & 60 & $3^{\circ}$ & - & - \\
\hline $4^{\circ}$ & $\begin{array}{c}\text { CCET } \\
\text { CELA97 } \\
2\end{array}$ & $\begin{array}{l}30 \\
60\end{array}$ & $4^{\circ}$ & - & - & $4^{\circ}$ & $\begin{array}{c}\text { MATGI22 }_{4} \\
\end{array}$ & 60 \\
\hline $5^{0}$ & $\begin{array}{c}\text { CELAos } \\
9 \\
\text { CCET }\end{array}$ & $\begin{array}{l}60 \\
75\end{array}$ & $5^{\circ}$ & $3 \mathrm{I}$ & 45 & $5^{\circ}$ & - & - \\
\hline 60 & $\begin{array}{c}\text { CELA74 } \\
5 \\
\text { CCET }\end{array}$ & $\begin{array}{l}60 \\
60\end{array}$ & 60 & 37 & 60 & 60 & - & - \\
\hline $7^{0}$ & CCET & 75 & $7^{\circ}$ & - & - & $7^{\circ}$ & $\begin{array}{l}\text { MATG25I } \\
7\end{array}$ & 25 \\
\hline 8 은 & CCET & 135 & $8^{\circ}$ & - & - & $8^{\circ}$ & $\begin{array}{l}\text { MATGi57 } \\
\quad 8\end{array}$ & 40 \\
\hline
\end{tabular}

Nota: Elaboração da autora.

Pode-se perceber um avanço nas práticas do PPCS 1 , mas os $\mathrm{PPCS}_{2}$ e $\mathrm{PPCS}_{3}$ ainda necessitam melhorar em relação a Prática de Ensino e, principalmente no que se refere as práticas de Estágio Supervisionado para cumprir as novas diretrizes de Educação Inclusiva. Apesar de algumas disciplinas optativas contemplarem o tema estudado, a quantidade ainda é ínfima, além de não ser possível garantir a escolha por parte do licenciando. Como consequência da ausência de uma quantidade de componentes significativos para abordar a Educação Inclusiva, "dificilmente o professor egresso do curso em questão poderá responder efetivamente às demandas impostas pelos contextos escolares nos quais atuará, principalmente em relação ao ensino de alunos com necessidades educacionais especiais" (Pedroso, Campos e Durate, 2013, p.45) 


\section{CONSIDERAÇÕES FINAIS}

Este estudo buscou analisar como os cursos de Licenciatura em Matemática do Estado do Acre tratam as questões de Educação Inclusiva em seus PPCS. As políticas de formação de professores em uma perspectiva inclusiva têm gerado mudanças significativas no currículo do curso de uma instituição, mas outras ainda necessitam de engajamento para atender a nova proposta. Várias medidas legais foram e continuam sendo tomadas para assegurar a inclusão de todos os alunos na escola, mas a ausência de preparo adequado tanto das instituições de ensino quanto dos professores que formam o futuro professor ainda é um complexo obstáculo a ser conquistado.

Observou-se a existência de lacunas na organização curricular dos cursos de formação inicial de professores de matemática e a maiorias das instituições possuem apenas três componente em suas matrizes curriculares, com baixa carga horária para atender a temática da inclusão. Fato que não garante os saberes pedagógicos basilares para responder às demandas da educação básica, principalmente em relação ao ensinoaprendizagem de alunos com alguma necessidade educacional especial, já que carecem trabalhar o seu modo de pensar e agir com o escopo de gerar uma identidade inclusiva.

Por fim, a mudança nos PPCS não seria apenas em componentes com conteúdo voltado para a Educação Inclusiva, mas sim de mudança de atitudes, concepções e valores para uma formação mais significativa, para esta pesquisadora. Ressalta-se que o estudo possibilitou a análise dos PPCS em instituições públicas do estado do Acre para saber como organizam suas matrizes curriculares em prol de uma Educação Inclusiva. Os dados obtidos indicam a necessidade de ir além e identificar as concepções norteadoras, os conteúdos priorizados e os referenciais teóricos selecionados.

\section{REFERÊNCIAS BIBLIOGRÁFICAS}

AINSCOW, M. (2009). Tornar a educação inclusiva: como esta tarefa deve ser conceituada. In Tornar a educação inclusiva, I, II-24. https://sid.usal.es/idocs/F8/FDO23183/tornar_educa\%C3\%A 7ao_inclusiva.pdf\#pa ge $=$ II 
ARAÚJO, K., \& Bazante, T. (2020). A importância da formação do professor de Matemática para a inclusão de alunos com discalculia. REnCiMa, São Paulo, II(7). https://revistapos.cruzeirodosul.edu.br/index.php/rencima/article/view/2647

BARDIN, L. (2016). Análise de conteúdo. Edições 70.

BARROS, D. D. (2017). Formação inicial de professores de matemática na perspectiva da educação inclusiva: contribuições da disciplina de Libras. https://repositorio.unesp.br/handle/II449/152464

BORGES, F. A., Cyrino, M. C. D. C. T., \& Nogueira, C. M. I. (2020). A formação do futuro professor de Matemática para a atuação com estudantes com deficiência: uma análise a partir de projetos pedagógicos de cursos. Boletim Gepem, (76), 134-155. http://costalima.ufrrj.br/index.php/gepem/article/view/515

BRASIL, C. C. (1988, 5 de outubro). Constituição da República Federativa do Brasil. Presidência da República. Casa Civil. Subchefia para Assuntos Jurídicos. Publicada em Brasília, 5 de outubro de 1988. http://www.planalto.gov.br/ccivil_03/constituicao/constituicao.htm

BRASIL, M.E.C. (1996, 20 de dezembro). Lei no 9.394/1996. Estabelece as Diretrizes e Bases da Educação Nacional. Congresso Nacional. Diário Oficial da União, 134(248). Publicada em Brasília, 20 de dezembro de 1996 , $185^{\circ}$ da Independência e ro8 ${ }^{\circ}$ da República. http://portal.mec.gov.br/seesp/arquivos/pdf/lei9394_ldbni.pdf

BRASIL, S.G.S.A.J. (2001, o9 de janeiro). Lei no $10.172 / 20001$. Aprova o Plano Nacional de Educação. Casa Civil da Presidência, Subchefia para Assuntos Jurídicos. Publicada em Brasília, 9 de janeiro de http://www.planalto.gov.br/ccivil_03/leis/leis_200I/lior72.htm

BRASIL, M.E.C. (2001, 6 de novembro). Parecer CNE/CES n ${ }^{\circ}$ 1.302/200I. Diretrizes Curriculares Nacionais para os Cursos de Matemática, Bacharelado e Licenciatura. http://portal.mec.gov.br/cne/arquivos/pdf/CESiz022.pdf

BRASIL, C.N.E. (2002, I8 de fevereiro). Resolução CNE/CP ı. Institui Diretrizes Curriculares Nacionais para a Formação de Professores da Educação Básica, em nível superior, curso de licenciatura, de graduação plena. Conselho Nacional de Educação. Conselho Pleno. Publicado em 18 de fevereiro de 2002. http://portal.mec.gov.br/index.php?option=com_doc man\&view=download \&alias= I5926I-rcpooI-02\&category_slug=outubro-2020-pdf \&Itemid $=30192$

BRASIL, C.C.S.A.J. (2002, 24 de abril). Lei № 10.436 . Dispões sobre Língua Brasileira de Sinais (LIBRAS). Casa Civil. Subchefia de Assuntos Jurídicos. Publicado em 24 de abril de 2002). http://www.planalto.gov.br/ccivil_03/leis/2002/lio436.htm 
Brasil, C.N.E. (2003, I8 de fevereiro). Resolução CNE/CES 3. Estabelece Diretrizes Curriculares Nacionais para os cursos de Matemática. Conselho Nacional de Educação. Câmara de Educação Superior. Publicado em 18 de fevereiro de 2003. http://portal.mec.gov.br/cne/arquivos/pdf/ceso32003.pdf

BRASIL, C.C.S.A.J. (2004, I4 de abril). Lei no 10.86I/2004. Institui o Sistema Nacional de Avaliação da Educação Superior - SINAES. Publicado em I4 de abril de 2004. http://www.planalto.gov.br/ccivil_03/_ato2004-2006/2004/lei/lı.86r.htm

BRASIL, C.C.S.A.J. (2005, 22 de dezembro). Decreto ${ }^{\circ} 5.626 / 2005$. Regulamenta a Lei no 10.436 , de 24 de abril de 2002, que dispõe sobre a Língua Brasileira de Sinais Libras, e o art. I8 da Lei no 10.098 , de 19 de dezembro de 2000. Casa Civil. Subchefia para Assuntos Jurídicos. Publicado em 22 de dezembro de 2005. http://www.planalto.gov.br/ccivil_03/_ato2004-2006/2005/decreto/d5626.htm

Brasil, M.E.C. (2006). Secretaria de Educação Especial. Programa Educação Inclusiva: direito à diversidade. http://portal.mec.gov.br/pet/194-secretarias-II2877938/secadeducacao-continuada-22336954I/17434-programa-educacao-inclusiva-direito-adiversidade-novo

BRASIL, M.E.C. (2008, Janeiro/Junho). Política Nacional de Educação Especial na Perspectiva da Educação Inclusiva. Inclusão: Revista da Educação Especial, 4(I), 6 I. http://portal.mec.gov.br/seesp/arquivos/pdf/revinclusao5.pdf

BRASIL, M.E.C. (2010, I7 de junho). Resolução n I/ 2oro. Normatiza o Núcleo Docente Estruturante. Comissão Nacional de Avaliação da Educação Superior. Publicado em 17 de junho de 2010. http://portal.mec.gov.br/index.php?option =com_docman\&view =download \&alias= 6885-resolucaor-2010-conae\&category_slug=outubro-2010-pdf \&Itemid=30192

BRASIL, M.E.C. (2010, i7 de junho). Parecer CONAES n 4/2010. Sobre o Núcleo Docente Estruturante - NDE. Publicado em i7 de junho de 2010. https://www.udesc.br/arquivos/esag/id_cpmenu/640/com_despacho_conaes__p arecer_n_4__nde_I528236056120I_640.pdf

BRASIL, M.E.C. (2015, I de julho). Resolução CNE/CP no 2/2015. Define as Diretrizes Curriculares Nacionais para a Formação Inicial em Nível Superior (Cursos de Licenciatura, Cursos de Formação Pedagógica para Graduandos e Cursos de Segunda Licenciatura) e para a Formação Continuada. Conselho Nacional de Educação. Conselho Pleno. Publicado em I de julho de 2015. http://portal.mec.gov.br/index.php?option=com_docman\&view =download $\&$ alias $=$ 136731-rcpoo2-I5-I\&category_slug=dezembro-2019-pdf\&Itemid=30192

CANASSA, V. \& Borges, F. A. (2020). A Constituição do papel do professor que ensina matemática na Educação Inclusiva: uma análise a partir da legislação 
brasileira. RECeT-Revista de Educação, Ciência e Tecnologia. I(I), 7-28. https://ojs.ifsp.edu.br/index.php/recet/article/view/162o

D’Ambrósio, U. (2013). Por que se ensina Matemática. Acesso em, 3. https://edisciplinas.usp.br/pluginfile.php/5793818/mod_resource/content/I/Ubirat an\%20DAmbrosio\%20-\%20Por\%20que\%20se\%20ensina\%20matem\%C3\%Artica.pdf

DA COSTA, P. K. A., da Silva, S. D. C. R., \& Noronha, A. M. (2021). Formação Inicial de Professores de Matemática na Perspectiva da Educação Inclusiva. REMATEC, $16(38)$,

http://www.rematec.net.br/index.php/rematec/article/view/333

DE PAUlA, T. E., Guimarães, O. M., \& da Silva, C. S. (2018). Formação de professores de química no contexto da educação inclusiva. Alexandria: Revista de $\begin{array}{lllll}\text { Educação em } \quad \text { Ciência } & \text { 3-29. }\end{array}$ https://dialnet.unirioja.es/servlet/articulo?codigo=6555439

GIL, A. C. (2017). Como elaborar projetos de pesquisa. (6- Ed.). Editora Atlas.

IFAC, P.P.C.S. (2017, 23 de junho). Resolução CONSU/IFAC № 027/2017. Dispõe sobre o Projeto Pedagógico do Curso Superior de Licenciatura em Matemática do Campus Rio Branco, do Instituto Federal de Educação, Ciência e Tecnologia do Acre. Boletim interno Extraordinário Junho. https://sig.ifac.edu.br/sigaa/RESOLUÇÃO/CONSU/IFACNoo27/2017

IFAC, P.P.C.S. (2018, o4 de maio). Resolução CONSU/IFAC № 024/2018. Dispõe sobre o Projeto Pedagógico do Curso Superior de Licenciatura em Matemática do Campus Cruzeiro do Sul, do Instituto Federal de Educação, Ciência e Tecnologia do Acre. Boletim interno Extraordinário Junho. 7(32). https://sig.ifac.edu.br/sigaa/RESOLUÇÃO/CONSU/IFACNoo24/2018

KNECHTEL, M. D. R. (2014). Metodologia da pesquisa em educação: uma abordagem teórico-prática dialogada. Editora Intersaberes.

KRANZ, C. R. (20II). Os jogos na educação matemática inclusiva. XIII Conferência interamericana de educação matemática. http://xiii.ciaemredumate.org/index.php/xiii_ciaem/xiii_ciaem/paper/viewFile/1730/394

MARCATTO, F. S. F. (2012). A prática como componente curricular em projetos pedagógicos de cursos de licenciatura em matemática. http://portal.mec.gov.br/cne/arquivos/pdf/ceso32003.pdf

PEDroso, C. C. A., Campos, J. A. D. P. P., \& Duarte, M. (2013). Formação de professores e educação inclusiva: análise das matrizes curriculares dos cursos de $\begin{array}{ll}\text { licenciatura. Educação } \quad \text { Unisinos, }{ }_{17}(\mathrm{I}), & 40-47 .\end{array}$ http://revistas.unisinos.br/index.php/educacao/article/view/edu.2013.171.05/14II 
Pimentel, S. C. (2012). Formação de professores para a inclusão: saberes necessários e percursos formativos. In Miranda, T. G., \& Galvão Filho, T. A. (2012). O professor e a educação inclusiva: formação, práticas e lugares. Salvador: EDUFBA, I39-I55.

Pimentel, L. D. S. (2015). Possíveis indícios de discalculia em Anos Iniciais: uma análise por meio de um Teste piloto de Matemática [Dissertação do Programa de Mestrado em Educação da Pontifícia Universidade Católica do Rio Grande do Sul Goiás]. https://repositorio.pucrs.br/dspace/bitstream/I0923/7520/I/oo0473751-

Texto+Completo-o.pdf

RAMOS, L. (2015). Formando Professores de Matemática para uma Educação Matemática Inclusiva:(re) significando concepções sobre ensino e aprendizagem de geometria de alunos com deficiência. Encontro Brasileiro de Estudantes de PósGraduação em Educação https://www.ufjf.br/ebrapem2ors/files/2015/ro/gdi3_Leiliane_Ramos.pdf

RODRIGUES, T. D. (2015). Educação matemática inclusiva. Interfaces da educação, I (3),

https://periodicosonline.uems.br/index.php/interfaces/article/view/620/584

SACRISTÁN, J. G. (2013). Saberes e incertezas sobre o currículo. Penso Editora.

UFAC, P.P.C. (2018, 20 de março). Projeto Pedagógico do Curso de Licenciatura em Matemática. Universidade Federal do Acre (Reformulação). Pró-Reitoria de Graduação. Centro de Ciências Exatas e Tecnológicas. http://www2.ufac.br/ccet/matematica/projetos-pedagogicos/ppc-atual/ppcmatematica-versao-2018-20-03-2018-nde.pdf/view

Unesco. (1994). Declaração de Salamanca sobre princípios, políticas e práticas na área das necessidades educativas especiais. https://pnl2027.gov.pt/np4/\%7B $\$$ clientServletPath\%7D/?newsId=ıir \&fileName= Declaracao_Salamanca.pdf 